\title{
An unusual location of hand, foot and mouth disease
}

\author{
Enrico Di Lella ${ }^{1} \cdot$ Flavia Angelini $^{2} \cdot$ Sarah Campagnano ${ }^{2} \cdot$ Daniela Messineo $^{2} \cdot$ Francesco Maria Drudi $^{2}$
}

Received: 9 November 2020 / Accepted: 13 January 2021 / Published online: 20 March 2021

(c) Società Italiana di Ultrasonologia in Medicina e Biologia (SIUMB) 2021

\begin{abstract}
Hand, foot, and mouth disease (HFMD) is a childhood febrile disease. Oral lesions and papulovesicular lesions on the hands and feet are the clinical signs of the disease. In our case, a 17-year-old boy presented to the emergency department, where he was diagnosed with HFMD. After 6 days, he felt intense pain in his right testicle, and therefore an ultrasound (US) examination was performed. US detected a hypoechoic mass-like area in the right testis. Viral etiology was suspected, and no therapy was prescribed. After a little more than 3 months, US examination showed a reduced lesion size. Viral epididymo-orchitis should be suspected in young men with a recent history of HFMD and testicular pain.
\end{abstract}

Keywords HFMD · Orchitis · Epididymo-orchitis · Coxsackie virus · Ultrasound

\section{Background}

Hand, foot, and mouth disease (HFMD) is a childhood febrile disease first described by Robinson et al. in Toronto in 1957 [1]. It is caused mainly by coxsackievirus A16, enterovirus 71, coxsackievirus A6, and coxsackievirus A10 [1-3]. HFMD usually occurs in spring and summer [4] and most often in children from 0 to 5 years of age $[5,6]$ and immunocompromised adults [7], as they may be especially vulnerable to enterovirus 71 and coxsackievirus A16 [8] infections. However, HFMD can also occur in immunocompetent adults $[6,7]$. The main routes of transmission are through oropharyngeal secretions or by direct contact with cutaneous lesions, faeces [9], and contaminated objects. The incubation period is short, ranging from 2 to 7 days. Oral lesions are the first clinical signs of the disease, and they are sometimes the only signs, as they appear before the lesions on the extremities [9]. Cutaneous manifestations include multiple papulovesicular lesions on the hands and feet. In most cases, the prognosis is good, with spontaneous healing in 7-10 days without sequelae. Treatment is only

Francesco Maria Drudi

francescom.drudi@uniroma1.it

1 Department of Radiology, S. Filippo Neri Hospital, Rome, Italy

2 Department of Radiological, Oncological and Pathobiological Sciences, Sapienza University of Rome, Rome, Italy symptomatic, also because a virus-specific therapy is not available [10].

\section{Case report}

A 17-year-old boy presented to the emergency department with a 4-day history of pharyngitis, general discomfort, and a progressive papulovesicular rash that had started on his palms and subsequently involved his nose and feet. He was diagnosed with HFMD. He underwent chest X-ray, blood tests, and an electrocardiogram; a lesional polymerase chain reaction (PCR) swab was positive for coxsackievirus. No specific therapy was administered. After 6 days, he felt intense pain in his right testicle. He had a mild fever and a swelling on the right side of the scrotum, and there was tenderness on palpation. Testicular torsion was suspected, and an ultrasound (US) examination was therefore performed. US revealed a hypo-isoechoic mass-like area on the right side, with a maximum longitudinal diameter of $19.3 \mathrm{~mm}$, but no signs of vascularization were found at a color Doppler US examination (Fig. 1). With the exception of the hypoisoechoic area, the testis appeared only slightly increased in size and showed regular vascularization on color Doppler. Nevertheless, orchitis was suspected. No therapy was administered. After 2 weeks, US was repeated, showing that the hypoechoic area was reduced; in particular, the longitudinal diameter was reduced from 19.3 to $17.8 \mathrm{~mm}$ (Fig. 2). Viral etiology was suspected. A little more than 3 months later, 


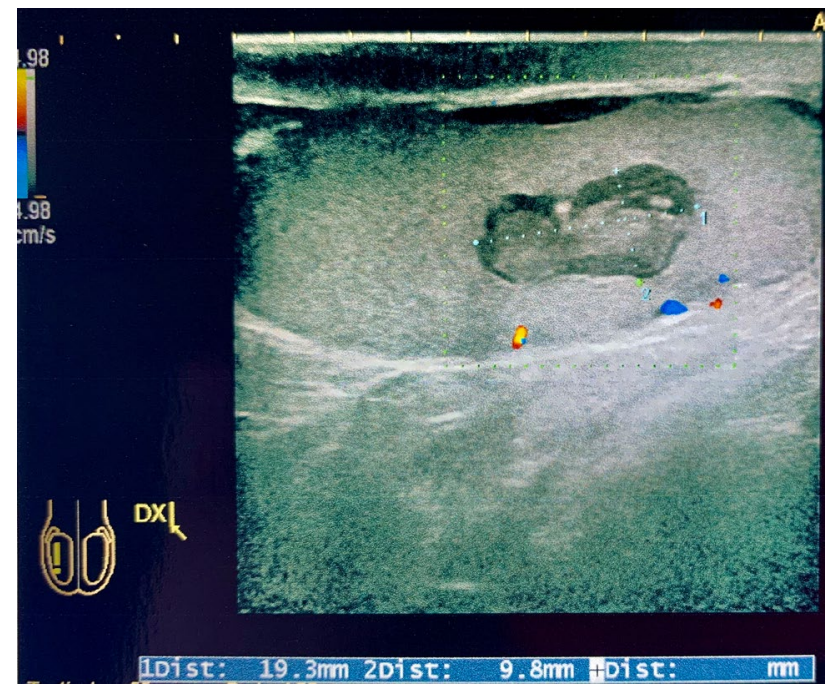

Fig. 1 First US examination: a hypoechoic mass-like area in the right testis, with a maximum longitudinal diameter of $19.3 \mathrm{~mm}$ and no signs of vascularization at color Doppler US

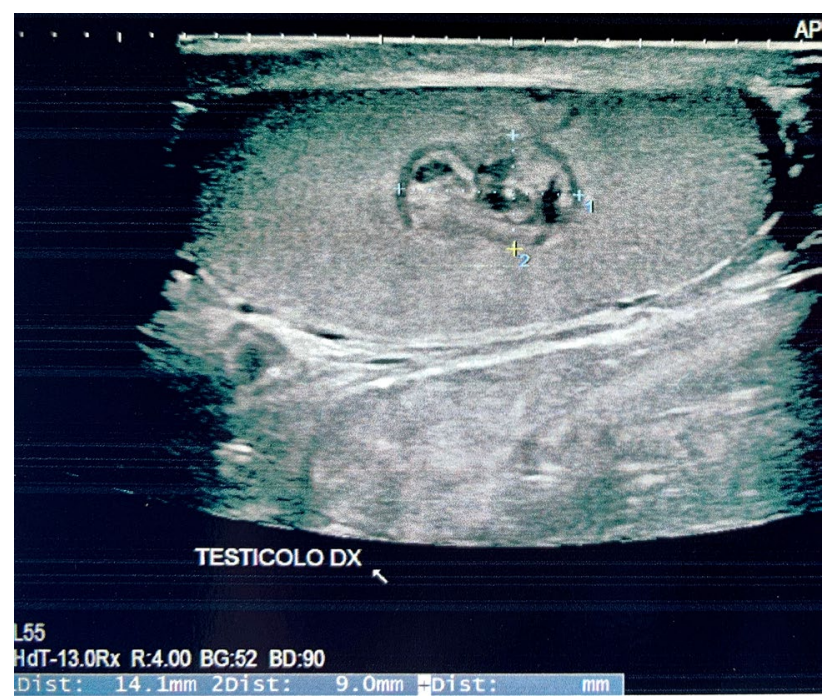

Fig. 2 Second US examination: the hypoechoic area is reduced from 19.3 to $17.8 \mathrm{~mm}$

US examination showed a further reduction in lesion size, from 17 to $7.5 \mathrm{~mm}$. Moreover, the lesion appeared more isoechoic (Fig. 3).

\section{Discussion}

Viral infection is a potential cause of orchitis independently of age [11]. The mumps virus is most commonly involved, but other viruses, such as adenovirus and enterovirus, are also seen $[11,12]$. Coxsackievirus, known for causing

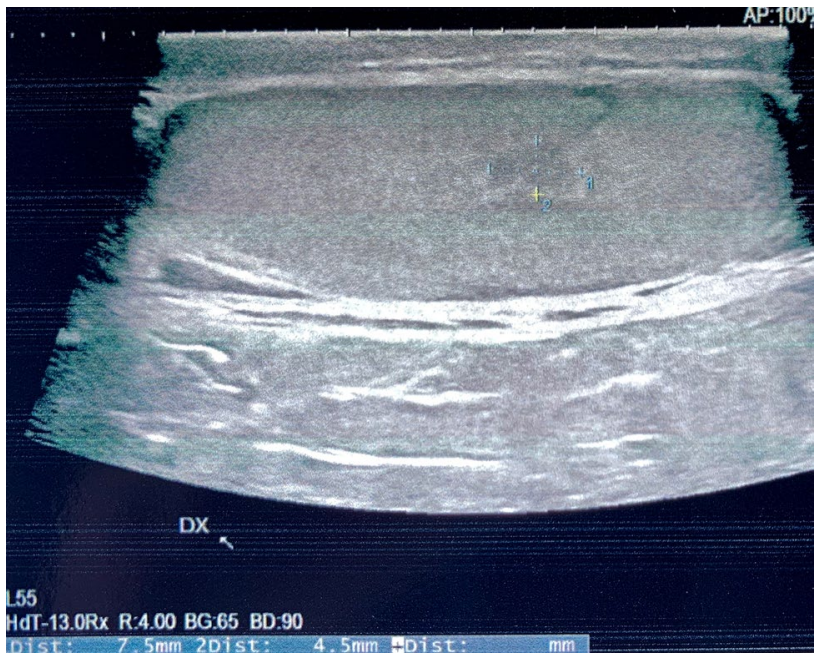

Fig. 3 Third US examination: the lesion size is further reduced from 17.8 to $7.5 \mathrm{~mm}$. The lesion appeared more isoechoic

HFMD, is a type of enterovirus that has been documented as a cause of orchitis. In a case report by Vuorinen et al. [13], a 17-year-old male patient with a diagnosis of HFMD developed epididymo-orchitis caused by coxsackievirus A6 (CV-A6), which is a member of human enterovirus species $\mathrm{A}$ in the genus Enterovirus in the family Picornaviridae. In 2008, CV-A6 became known as a cause of HFMD [14]. The characteristics of CV-A6 HFMD are atypical and more severe than those seen in the classic disease, and adults have also been affected [14-17].

La Marca et al. [18] recently reported a case of a young man presenting heavy testicular pain as the first symptom of a COVID-19 infection. Fernandino et al. [19] presented a case similar to ours: a 41-year-old patient with bilateral scrotal masses and a recent previous diagnosis of HFMD. As in our case, the patient underwent only US follow-up, which demonstrated the benignity of the lesion. Tumor markers (alpha fetoprotein, beta-human chorionic gonadotropin) were detected and were within normal limits.

In our case, we first ruled out that it was testicular torsion. We did not find it necessary to detect tumor markers because the lesion on US was not highly suggestive of a malignant lesion [20, 21]; it had no signs of vascularization at color Doppler US as we would expect in a solid mass, and it was reduced in size after 2 weeks.

Moreover, the clinical history did not provide a suspicion of a malignant lesion: the onset of the testicular lesion right after the onset of common HFMD symptoms, and its spontaneous regression, without any therapy, was highly suggestive of a testicular location of HFMD, so no histological analysis was performed. However, the US examination did not show the typical signs of orchitis: increased size of the testis and increased vascularization at color Doppler [22]. 
The hypo-isoechoic mass-like area we found could have been caused by inflammation, fibrosis, or hematoma with infarcted seminiferous tubules.

Hurtt et al. [12] recently presented two similar cases of unilateral viral-induced testis masses. Both patients underwent orchiectomies because of a high level of anxiety over potential malignancy. Fortunately, both cases were negative for malignancy.

In order to avoid unnecessary invasive procedures, anamnesis should include recent upper respiratory or gastrointestinal infections.

Some authors claim that serological studies are not indicated routinely in epididymo-orchitis as they are unlikely to influence the management; whether radiological investigations are necessary is controversial [23]. Some authors recommend renal ultrasonography and cystography in every prepubertal case of acute epididymo-orchitis [24]: renal/ bladder ultrasonography and cystourethrography for young boys ( $<5$ years) with epididymitis; and uroflowmetry, ultrasonography, and detailed questioning of voiding symptoms for older children ( $>10$ years).

\section{Conclusion}

HFMD is a typical childhood disease, but it may also occur in adults, which should be kept in mind because of the possibility of outbreaks. Viral epididymo-orchitis should be suspected in young men with a recent history of HFMD who present with testicular pain. It is important to recognize this unusual clinical presentation to avoid unnecessary invasive procedures or inappropriate antibiotic treatments.

\section{Compliance with ethical standards}

Conflict of interest The authors declare that they have no conflict of interest.

Ethics approval All procedures performed in studies involving human participants were in accordance with the ethical standards. Informed consent was obtained.

\section{References}

1. Robinson CR, Doane FW, Rhodes AJ (1958) Report of an outbreak of febrile illness with pharyngeal lesion and exanthem: Toronto, summer 1957; isolation of group A coxsackie virus. Can Med Assoc J 79:615-621

2. Kaminska K, Martinetti G, Lucchini R, Kaya G, Mainetti C (2013) Coxsackievirus A6 and hand, foot and mouth disease: three case reports of familial child-to-immunocompetent adult transmission and a literature review. Case Rep Dermatol 5(2):203-209. https:// doi.org/10.1159/000354533
3. Campbell L, Chu Y, Introcaso C, Scha er A, James W, (2013) Coxsackievirus A6-induced hand-foot-mouth disease. JAMA Dermatol 149(12):1419-1421. https://doi.org/10.1001/jamad ermatol.2013.6777

4. Blomqvist S, Klemola P, Kaijalainen S, Paananen A, Simonen ML, Vuorinen T et al (2010) Co-circulation of coxsackieviruses A6 and A10 in hand, foot and mouth disease outbreak in Finland. J Clin Virol 48:49-54

5. Wang Y, Feng Z, Yang Y, Self S, Gao Y, Longini IM, Wakefield J, Zhang J, Wang L, Chen X, Yao L, Stanaway JD, Wang Z, Yang W (2011) Hand, foot, and mouth disease in China: patterns of spread and transmissibility. Epidemiology 22(6):781792. https://doi.org/10.1097/EDE.0b013e318231d67a

6. Zhang X, Yan HP, Huang C, Tan YF, Ma DM, Zhang HP, Liu Y, Wang SZ (2009) The etiology and clinical manifestations of 70 patients with hand-foot-mouth disease. Zhonghua Yu Fang Yi Xue Za Zhi 43(10):872-874 ((Chinese), PMID: 20137466)

7. Shin JU, Oh SH, Lee JH (2010) A case of hand-foot-mouth disease in an immunocompetent adult. Ann Dermatol 22:216-218

8. Ooi MH, Wong SC, Mohan A, Podin Y, Perera D, Clear D, del Sel S, Chieng CH, Tio PH, Cardosa MJ, Solomon T (2009) Identification and validation of clinical predictors for the risk of neurological involvement in children with hand, foot, and mouth disease in Sarawak. BMC Infect Dis 19(9):3. https://doi.org/10. 1186/1471-2334-9-3

9. Park SK, Park B, Ki M, Kim H, Lee K, Jung C, Sohn YM, Choi SM, Kim DK, Lee DS, Ko JT, Kim MK, Cheong HK (2010) Transmission of seasonal outbreak of childhood enteroviral aseptic meningitis and hand-foot-mouth disease. J Korean Med Sci 25(5):677-683. https://doi.org/10.3346/jkms.2010.25.5.677 (Epub 21 Apr 2010)

10. Omaña-Cepeda C, Martínez-Valverde A, del Mar M, Recolons S, Jané-Salas E, Marí-Roig A, López-López J (2016) A literature review and case report of hand, foot and mouth disease in an immunocompetent adult. BMC Res Notes 9:165

11. Osterback R, Tevaluoto T, Ylinen T, Peltola V, Susi P, Hyypiä T, Waris M (2013) Simultaneous detection and differentiation of human rhino- and enteroviruses in clinical specimens by realtime RT-PCR. J Clin Microbiol 51:3960-3967. https://doi.org/ 10.1128/JCM.01646-13

12. Hurtt R, Pound C, Bean C (2017) Benign testis mass after viral infection. Urol Case Rep 14(12):4-5. https://doi.org/10.1016/j. eucr.2017.01.001.PMID:28224088;PMCID:PMC5312462

13. Vuorinen T, Osterback R, Kuisma J, Ylipalosaari P (2014) Epididymitis caused by coxsackievirus A6 in association with hand, foot, and mouth disease. J Clin Microbiol 52(12):44124413. https://doi.org/10.1128/JCM.02441-14 (Epub 17 Sep 2014)

14. Osterback R, Vuorinen T, Linna M, Susi P, Hyypiä T, Waris M (2009) Coxsackievirus A6 and hand, foot, and mouth disease. Finland Emerg Infect Dis 15:1485-1488. https://doi.org/10.3201/ eid1509.090438

15. Sinclair C, Gaunt E, Simmonds P, Broomfield D, Nwafor N, Wellington L, Templeton K, Willocks L, Schofield O, Harvala H (2014) Atypical hand, foot, and mouth disease associated with coxsackievirus A6 infection, Edinburgh, United Kingdom, January to February 2014. Euro Surveill 19(12):20745. https://doi.org/ 10.2807/1560-7917.es2014.19.12.20745 (PMID: 24698138)

16. Ben-Chetrit E, Wiener-Well Y, Shulman LM, Cohen MJ, Elinav H, Sofer D, Feldman I, Marva E, Wolf DG (2014) Coxsackievirus A6-related hand foot and mouth disease: skin manifestations in a cluster of adult patients. J Clin Virol 59:201-203. https://doi.org/ 10.1016/j.jcv.2013.12.012

17. Downing C, Ramirez-Fort MK, Doan HQ, Benoist F, Oberste MS, Khan F, Tyring SK (2014) Coxsackievirus A6 associated hand, foot and mouth disease in adults: clinical presentation and 
review of the literature. J Clin Virol 60:381-386. https://doi.org/ 10.1016/j.jcv.2014.04.023

18. La Marca A, Busani S, Donno V, Guaraldi G, Ligabue G, Girardis M (2020) Testicular pain as an unusual presentation of COVID19: a brief review of SARS-CoV-2 and the testis. Reprod Biomed Online 41(5):903-906. https://doi.org/10.1016/j.rbmo.2020.07. 017 (Epub 23 Jul 2020, PMID: 32826162)

19. Fernandino LV, Steven YL, Bogdana S (2020) Resolution of bilateral testicular masses after viral infection. Urol Case Rep 33:101388. https://doi.org/10.1016/j.eucr.2020.101388 (PMCID: PMC7574037; 33102086)

20. Brillantino C, Rossi E, Minelli R, Irace D, Castelli L, Zeccolini R, Bignardi E, Tufano A (2019) A rare case of renal tumor in children: clear cell sarcoma. G Chir 40(3):217-224 (PMID: 31484012)

21. Brillantino C, Rossi E, Bifano D, Minelli R, Tamasi S, Mamone R, Bignardi E, Zeccolini R, Zeccolini M, Vallone G (2020) An unusual onset of pediatric acute lymphoblastic leukemia. J Ultrasound. https://doi.org/10.1007/s40477-020-00461-y
22. Artul S, Abu Rahmah Y, Abu Shkara H, Yamini A (2014) Inferno: colour Doppler ultrasound sign of orchitis. BMJ Case Rep. https://doi.org/10.1136/bcr-2014-203613 (PMID: 24692383; PMC3987535)

23. Gkentzis A, Lee L (2014) The aetiology and current management of prepubertal epididymitis. Ann R Coll Surg Engl 96(3):181183. https://doi.org/10.1308/003588414X13814021679311 (PMID: 24780779; PMC4474044)

24. Siegel A, Snyder H, Duckett JW (1987) Epididymitis in infants and boys: underlying urogenital anomalies and efficacy of imaging modalities. J Urol 138:1100-1103

Publisher's Note Springer Nature remains neutral with regard to jurisdictional claims in published maps and institutional affiliations. 